\title{
The Effect of Structural Rigidity Uncertainties on ATMD Controlled Structures
}

\author{
AYLİN ECE KAYABEKİR ${ }^{1}$, GEBRAİL BEKDAŞ ${ }^{2 *}$, SINAN MELİH NİGDELİ ${ }^{2}$ \\ ${ }^{1}$ Civil Engineering Department, \\ Istanbul Gelişim University \\ 34310 Avc1lar, Istanbul, TURKEY \\ ${ }^{2}$ Civil Engineering Department \\ Istanbul University - Cerrahpaşa \\ 34310 Avc1lar, Istanbul, TURKEY
}

\begin{abstract}
For efficiency of active control systems for seismically excited structures, and optimization process in need. This optimum design is defined according to the certain properties of structures, whereas the structural properties are found via several assumptions done in material strengths calculations and variable loading. These factors affect the mass and stiffness of the structure, but it is known that the main factor in the optimum design of control systems is the frequency that is related to mass and stiffness, generally. In this study, the stiffness of multiple degrees of freedom structure was reduced and increased to investigate the effect of the robustness of optimum active control systems for uncertainties. The numerical examination is done for a structure with an active tuned mass damper (ATMD) that is positioned on the top of the structure. For \pm 20 stiffness change of structure, the efficiency of ATMD is between $0.99 \%$ and $12.63 \%$ for the reduction of maximum displacement.
\end{abstract}

Key-Words: - Robustness, uncertainties in structures, stiffness, active tuned mass damper

Received: May 26, 2021. Revised: December 27, 2021. Accepted: January 24, 2022. Published: February 15, 2022.

\section{Introduction}

The known history of the world has witnessed a constant change and adaptation of human beings due to their struggle with nature. Especially in recent years, with the number of people approaching approximately 8 billion, the changing and diversifying needs of people led to a rapid change in the face of the world. This change occurs in almost every aspect of life, such as the increase in the rate of urbanization, the rise of buildings, the increase in energy needs, the expansion of high-speed train networks and highways due to the need for a global supply chain and urbanization. However, this change brings with it new problems that need to be solved. This change and diversity in structural systems require them to produce new and innovative solutions, especially for structural engineers who have an important responsibility in the creation of the infrastructure of this change.

Structural control systems developed as a part of these solutions are among the systems that are frequently used in order to provide structural safety and comfort against earthquake and wind-like vibrations, especially in developed countries in the earthquake zone. Tuned mass dampers have an important place in terms of structural application area among control systems with active, passive, semi-active and hybrid-like varieties. In the field of practical application, this situation has also led to a lot of research on tuned mass dampers.

Some of the scientific studies related to active tuned mass dampers investigated in this study are mentioned in this section.

In 1996, Ankireddi and Yang investigated the effectiveness of the ATMD system against structural responses caused by wind loads in tall buildings [1]. The effectiveness of the isolation systems attached to TMD and ATMD controlled structures was examined by Loh and Chao [2]. Yan et al. obtained analytical expressions to be used in calculating the control force [3]. The performances of FLC (Fuzzy Logic Controller) and LQG (linear quadratic Gaussian) on vibrations control of tall buildings controlled with ATMD against along wind excitations was tested by Aldawod et al. [4]. In the study, a 76-story building in Melbourne, Australia was considered, and it was concluded that the FLC algorithm has slightly better performance. A similar study was also conducted by Samali et al. and it is demonstrated that the performance of the FLC 
algorithm is better than LQG [5]. Active multi-tuned mass dampers (AMTMDs) have also been investigated and suggested to be used to reduce structural vibration due to ground motion [6-10].

In the other study, Pourzeynali et al. developed a method combining genetic algorithm (GA) and FLC to suppress vibration of high rise buildings under seismic excitations [11]. Guclu ve Yazici examined the ATMD system using PD (proportional+ derivative) control and FLC. Accordingly, it was concluded that FLC has more effective active control performance [12]. Then, a combination of PID (proportional+integral and derivative) control and FLC was proposed [13]. FLC algorithm was also modified with a selftunning mechanism to improve control strategy [14]. Li et al. introduced a design methodology for AMTMD to attenuate translational and torsional responses in asymmetric structures [15]. In the other study, Li also considered soil-structure interaction (SSI) for AMTMD attached to asymmetric structures [16]. A hybrid system consisting of ATMDs was proposed for retrofit of irregular buildings against translational and torsional responses due to seismic excitations by Venanzi and Materazzi [17]. Then, a methodology using a hybrid system was developed to reduce flexural and torsional responses in tall buildings [18]. Sugumar et al. compared stochastic algorithm and LQG regulator for building frames with ATMD. In the study, the stochastic algorithm provided more effective seismic control [19]. Amini et al. employed particle swarm optimization (PSO) and linear quadratic regulator (LQR) in the calculation of active force. The study demonstrated that PSO provides better solutions for the structures subjected to near-fault excitations [20]. Fitzgerald et al. implemented ATMD to a wind turbine to control inplane vibrations of blades [21].

In 2014, two identical ATMDs were applied to the $90^{\text {th }}$ story of The Shanghai World Financial Center Tower by Lu et al. against wind loads [22]. Shariatmadar and Meshkat Razavi introduced an active control procedure using both PSO and FLC [23]. Soleymani and Khodadadi presented a multiobjective methodology using GA and FLC in order to mitigate dynamic vibrations due to earthquake and wind loads. The method was tested on a benchmark 76-story building in Australia, Melbourne. However, the optimum design against earthquake excitations was not adequate for the reduction of wind-induced vibrations and vice versa [24]. Considering similar building, the cuckoo search (CS) algorithm was proposed to be involved in the calculation process of active forces by Zabihi
Samani and Amini [25]. For the seismically excited high-rise buildings, PD, PID and LQR controllers were also examined. Under strong ground motions, PD and PID had superior performance than LQR. Additionally, PID was more effective in the mitigation of structural responses than PD [26]. In 2018, Heidari et al. suggested the use of a hybrid controller including LQR and PID controller to attenuate seismic excited vibrations. In the design of this hybrid controller, CS was employed [27]. Park et al. developed a control procedure based on a coupling type ATMD for adjacent buildings [28]. To improve seismic control of super-tall buildings, $\mathrm{Li}$ and Cao proposed an inerter to integrate into the ATMD system [29]. In the other study, an optimal design methodology-based sliding mode control was presented [30]. For the optimum tuning of ATMDs, metaheuristic algorithms were also investigated [3135]. Also, these algorithms have been used in various control systems [36-40].

As it is known, structural engineers perform their structural designs under various material and structural behavior presuppositions. However, regardless of the complexity of the calculations and the sophistication of the theory used, in any case, the existing parameters of the structure may differ from the values used in the design. Among the reasons for these are that the structure cannot be manufactured in accordance with the design acceptances, or the behavior is not in accordance with the acceptances, and it contains manufacturing (workmanship) defects. These can be added to the differences in the inhomogeneous behavior of concrete-like materials that are frequently used in buildings. All these situations may cause a risky situation in terms of structural security.

In this study, unlike the studies in the literature, the effect of uncertainties (differences) in the structural parameters that will occur due to the mentioned situations on the change of behavior of an ATMD-controlled structure has been examined. For this purpose, in an ATMD-controlled structure designed under certain structural stiffnesses, analyzes were made under eight different situations according to the deviations that may occur due to uncertainty in the floor stiffnesses. The analysis results of all cases were examined in detail in terms of the structure's behavior under earthquakes and structural displacements.

\section{Methodology}

In this section, the formulations of multiple degrees of freedom (MDOF) structure with an optimum ATMD on the top are presented. The formulations 
are given of an ATMD using proportional derivative integral (PID) type controllers that have optimum mass $\left(\mathrm{m}_{\mathrm{d}, \mathrm{opt}}\right)$, stiffness $\left(\mathrm{k}_{\mathrm{d}, \mathrm{opt}}\right)$, damping $\left(\mathrm{c}_{\mathrm{d}, \mathrm{opt}}\right)$, proportional gain $\left(\mathrm{K}_{\mathrm{p}, \mathrm{opt}}\right)$, derivative time $\left(\mathrm{T}_{\mathrm{d}, \mathrm{opt}}\right)$ and integral time $\left(\mathrm{T}_{\mathrm{i}, \mathrm{opt}}\right)$. The structure mass, stiffness and damping coefficients are shown as $\mathrm{m}_{\mathrm{i}}, \mathrm{k}_{\mathrm{i}}$ and $\mathrm{c}_{\mathrm{i}}$, respectively. $\mathrm{i}$ represent the story number. The uncertainty percentage is shown as $\mathrm{u}_{\mathrm{r}}$.

The equation of motion of structure is shown as Eq. (1) where $M, C$ and $K$ are mass, damping and stiffness, respectively. $\ddot{x}_{g}(t)$ is the ground acceleration. In this study, a set of far-fault ground motions presented in FEMA P-695 [41] are used and the results are presented for the most critical excitation. $\mathrm{F}(\mathrm{t})$ represents the control force matrix given as Eq. (2). $x(t)$ (Eq.3) is the response matrix including displacements of $\mathrm{N}$ story structure $\left(\mathrm{x}_{\mathrm{i}}\right.$ to $\left.\mathrm{x}_{\mathrm{N}}\right)$ and $\mathrm{ATMD}\left(\mathrm{x}_{\mathrm{d}}\right) . \mathrm{M}, \mathrm{K}$ and $\mathrm{C}$ matrices are shown as Eqs. (4)-(6). The control force $\left(F_{u}\right)$ is calculated via Eqs. (7)-(9). In these equations, $K_{f}, i_{A T M D}, R, K_{e}$, $\mathrm{u}(\mathrm{t}), \mathrm{t}_{\mathrm{d}}$ and $\mathrm{e}(\mathrm{t})$ are trust constant, armature coil, resistance value, induced voltage constant of armature coil, control signal, derivative time and error signal, respectively.

$\mathrm{M} \ddot{\mathrm{x}}(t)+\mathrm{C} \dot{\mathrm{x}}(t)+\mathrm{Kx}(t)=-\mathrm{M}\{1\} \ddot{x}_{g}(t)+\mathrm{F}(t)$

$\mathrm{F}(\mathrm{t})=\left\{\begin{array}{l}0 \\ 0 \\ \vdots \\ \mathrm{F}_{\mathrm{u}} \\ -\mathrm{F}_{\mathrm{u}}\end{array}\right\}$
$\mathrm{x}(\mathrm{t})=\left\{\begin{array}{l}\mathrm{x}_{1} \\ \mathrm{x}_{2} \\ \vdots \\ \mathrm{x}_{\mathrm{N}} \\ \mathrm{x}_{\mathrm{d}}\end{array}\right\}$

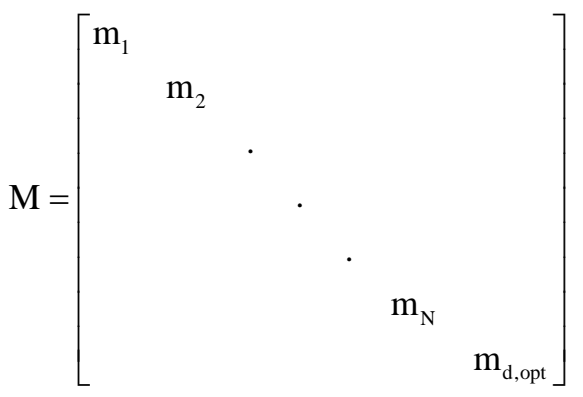

$\mathrm{K}=\left(\frac{100-\mathrm{u}_{\mathrm{r}}}{100}\left[\begin{array}{ccccccc}\left(\mathrm{k}_{1}+\mathrm{k}_{2}\right) & -\mathrm{k}_{2} & & & & \\ -\mathrm{k}_{2} & \left(\mathrm{k}_{2}+\mathrm{k}_{3}\right) & -\mathrm{k}_{3} & & & \\ & \cdot & \cdot & & & \\ & & \cdot & \cdot & & & \\ & & \cdot & -\mathrm{k}_{\mathrm{N}} & \left(\mathrm{k}_{\mathrm{N}}+\mathrm{k}_{\mathrm{d}, \text { opp }}\right) & -\mathrm{k}_{\mathrm{d}, \text { op }} \\ & & & & -\mathrm{k}_{\mathrm{d}, \text { op }} & \mathrm{k}_{\mathrm{d}, \text { pp }}\end{array}\right]\right.$

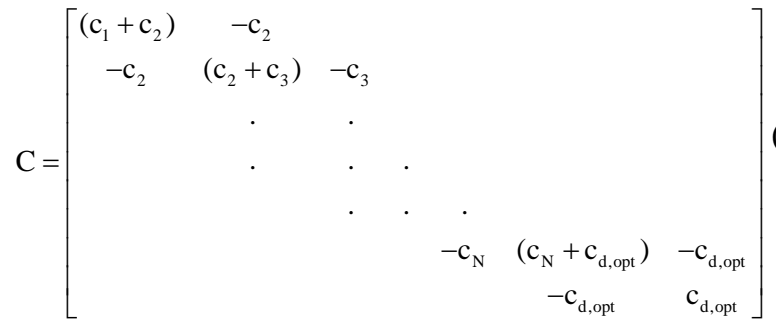

$\mathrm{F}_{\mathrm{u}}=\mathrm{K}_{\mathrm{f}} \mathrm{i}_{\mathrm{ATMD}}$

$\mathrm{Ri}_{\text {ATMD }}+\mathrm{K}_{\mathrm{e}}\left(\dot{\mathrm{x}}_{\mathrm{d}}-\dot{\mathrm{x}}_{\mathrm{N}}\right)=\mathrm{u}(\mathrm{t}-\mathrm{td})$

$u(t)=K_{p, o p t}\left[e(t)+T_{d, o p t} \frac{d e(t)}{d t}+\frac{1}{T_{i, o p t}} \int e(t) d t\right]$

The presented equations of motions are modeled in Matlab with Simulink [42] and the fourth-order Runge-Kutta method was used for time-history analysis by using the constant optimum ATMD parameters and changing stiffness values of structure.

\section{Numerical Examples}

In this section, the effect of story rigidity on the structural responses is investigated. For that reason, ten case analyzes are done for different story rigidity. In the analysis, a ten-story shear building with ATMD located to the top of the story is considered.

In the analysis, the optimum ATMD parameters that were previously founded by Jaya algorithm [35] are taken. Afterward, to examine the effect of stiffness uncertainties on the structural responses, analyzes were repeated for ten different cases in which the story stiffnesses is changed between $-25 \%$ and $25 \%$ by increasing $5 \%$ and the results were compared. The cases are shown with $\mathrm{u}_{\mathrm{r}}$ values and story stiffnesses are given in Table 1 . The value used in the optimization process was shown as constant. The structure and ATMD properties that are taken in the study are given in Table 2 .

For each case, critical earthquakes records that give the largest top story displacement among all records were found and their structural results were presented in Table 3. 
Table 1. Cases for different story rigidity

\begin{tabular}{cccccccccccc}
\hline Case No & $\mathbf{1}$ & $\mathbf{2}$ & $\mathbf{3}$ & $\mathbf{4}$ & $\mathbf{5}$ & constant & 6 & $\mathbf{7}$ & $\mathbf{8}$ & $\mathbf{9}$ & $\mathbf{1 0}$ \\
\hline $\mathrm{u}_{\mathrm{r}}(\%)$ & -25 & -20 & -15 & -10 & -5 & 0 & 5 & 10 & 15 & 20 & 25 \\
\hline $\begin{array}{c}\text { Rigidity coefficient } \\
\text { of each story } \\
(\mathrm{MN} / \mathrm{m})\end{array}$ & 487.5 & 520.0 & 552.5 & 585.0 & 617.5 & 650.0 & 682.5 & 715.0 & 747.5 & 780.0 & 812.5 \\
\hline
\end{tabular}

Table 2. The story and ATMD properties

\begin{tabular}{|c|c|c|c|c|}
\hline & Symbol & Definition & Value & Unit \\
\hline \multirow{3}{*}{$\begin{array}{l}\text { Story } \\
\text { properties }\end{array}$} & $m_{i}$ & Mass & 360 & ton \\
\hline & $k_{i}$ & Rigidity coefficient & $520-780$ & $\mathrm{MN} / \mathrm{m}$ \\
\hline & $c_{i}$ & Damping coefficient & 6.2 & $\mathrm{MNs} / \mathrm{m}$ \\
\hline \multirow{6}{*}{$\begin{array}{l}\text { Optimum } \\
\text { ATMD } \\
\text { parameters }\end{array}$} & $m_{d}$ & Mass & 180 & ton \\
\hline & $T_{\text {atmd }}$ & Period & 0.8923 & $\mathrm{~s}$ \\
\hline & $\xi_{d}$ & Damping ratio & 28.5447 & $\%$ \\
\hline & $K_{p}$ & Proportional gain & -336.3929 & $\mathrm{Vs} / \mathrm{m}$ \\
\hline & $T_{d}$ & Derivative time & 2003.7846 & $\mathrm{~s}$ \\
\hline & $T_{i}$ & Integral time & -6549.9725 & $\mathrm{~s}$ \\
\hline \multirow{4}{*}{$\begin{array}{l}\text { Constant } \\
\text { ATMD } \\
\text { parameters }\end{array}$} & stmax & Stroke limit & 2 & - \\
\hline & $R$ & Resistance value & 4.2 & $\Omega$ \\
\hline & $K_{f}$ & Trust constant & 2 & N/A \\
\hline & $K_{e}$ & Induced voltage constant of armature coil & 2 & $\mathrm{~V}$ \\
\hline
\end{tabular}

Table 3 . The top story displacements $\left(x_{10}\right)$ and accelerations $\left(\ddot{x}_{10}\right)$ for critical earthquakes

\begin{tabular}{ccccccc}
\hline $\begin{array}{c}\text { Case } \\
\text { no }\end{array}$ & $\begin{array}{c}\text { Earthquake } \\
\text { record }\end{array}$ & $x_{10}(\mathrm{~m})$ & $\ddot{x}_{10}\left(\mathrm{~m} / \mathrm{s}^{2}\right)$ & $\begin{array}{c}\text { Earthquake } \\
\text { record }\end{array}$ & $x_{10}(\mathrm{~m})$ & $\ddot{x}_{10}\left(\mathrm{~m} / \mathrm{s}^{2}\right)$ \\
\hline 1 & NORTHR/MUL279 & $\mathbf{0 . 2 7 7 3}$ & $\mathbf{9 . 5 5 1 0}$ & DUZCE/BOL090 & 0.2462 & 11.4665 \\
2 & NORTHR/MUL279 & $\mathbf{0 . 2 7 4 1}$ & $\mathbf{1 0 . 4 8 2 1}$ & DUZCE/BOL090 & 0.2507 & 12.4897 \\
3 & NORTHR/MUL279 & $\mathbf{0 . 2 6 8 7}$ & $\mathbf{1 1 . 3 1 1 3}$ & DUZCE/BOL090 & 0.2526 & 13.2650 \\
4 & NORTHR/MUL279 & $\mathbf{0 . 2 6 1 4}$ & $\mathbf{1 2 . 0 2 4 7}$ & DUZCE/BOL090 & 0.2523 & 13.7751 \\
5 & NORTHR/MUL279 & $\mathbf{0 . 2 5 2 8}$ & $\mathbf{1 2 . 8 0 4 5}$ & DUZCE/BOL090 & 0.2503 & 14.4433 \\
\hline opt & NORTHR/MUL279 & 0.2433 & 13.4350 & DUZCE/BOL090 & $\mathbf{0 . 2 4 6 9}$ & $\mathbf{1 4 . 8 4 1 3}$ \\
6 & NORTHR/MUL279 & 0.2334 & 13.9121 & DUZCE/BOL090 & $\mathbf{0 . 2 4 2 1}$ & $\mathbf{1 5 . 0 9 0 6}$ \\
7 & NORTHR/MUL279 & 0.2237 & 14.2290 & DUZCE/BOL090 & $\mathbf{0 . 2 3 6 5}$ & $\mathbf{1 5 . 4 6 8 5}$ \\
8 & NORTHR/MUL279 & 0.2146 & 14.3782 & DUZCE/BOL090 & $\mathbf{0 . 2 3 0 8}$ & $\mathbf{1 5 . 6 8 6 5}$ \\
9 & NORTHR/MUL279 & 0.2058 & 14.7806 & DUZCE/BOL090 & $\mathbf{0 . 2 2 4 9}$ & $\mathbf{1 6 . 0 0 8 3}$ \\
10 & NORTHR/MUL279 & 0.1971 & 15.0252 & DUZCE/BOL090 & $\mathbf{0 . 2 1 8 7}$ & $\mathbf{1 6 . 6 9 8 8}$ \\
\hline
\end{tabular}

From the analysis results, it is understood that critical earthquakes vary depending on the change in stiffness values. The critical earthquakes given in bold in the Table 3 are NORTHR/MUL279 record for $-25 \%--5 \%$ stiffness, and DUZCE/BOL090 record for others. Considering the critical earthquakes, the increase in stiffnesses led to a decrease in the displacements whereas an increase in the accelerations.

For the NORTH/MUL279 record, 9.69\% change in displacements, $34.06 \%$ in accelerations (Case 1-5), and for DUZCE/BOL090 record $12.89 \%$ change in displacements and $12.52 \%$ in accelerations (Caseopt-Case10) were observed.
Examining each case for both critical earthquakes, the difference between maximum displacements was found to be $0.99 \%-12.63 \%$. This difference was $8.47 \%-20.05 \%$ for maximum accelerations.

Also, for all cases accelerations decrease as stiffness increases, and DUZCE/BOL090 earthquake caused greater story accelerations.

Time history plots of top story displacements under critical earthquakes were also given in Fig 1 and 2 for 3 cases. From the figures, values and location of peek points of graphs differ depending on changing critical earthquakes, as expected. 


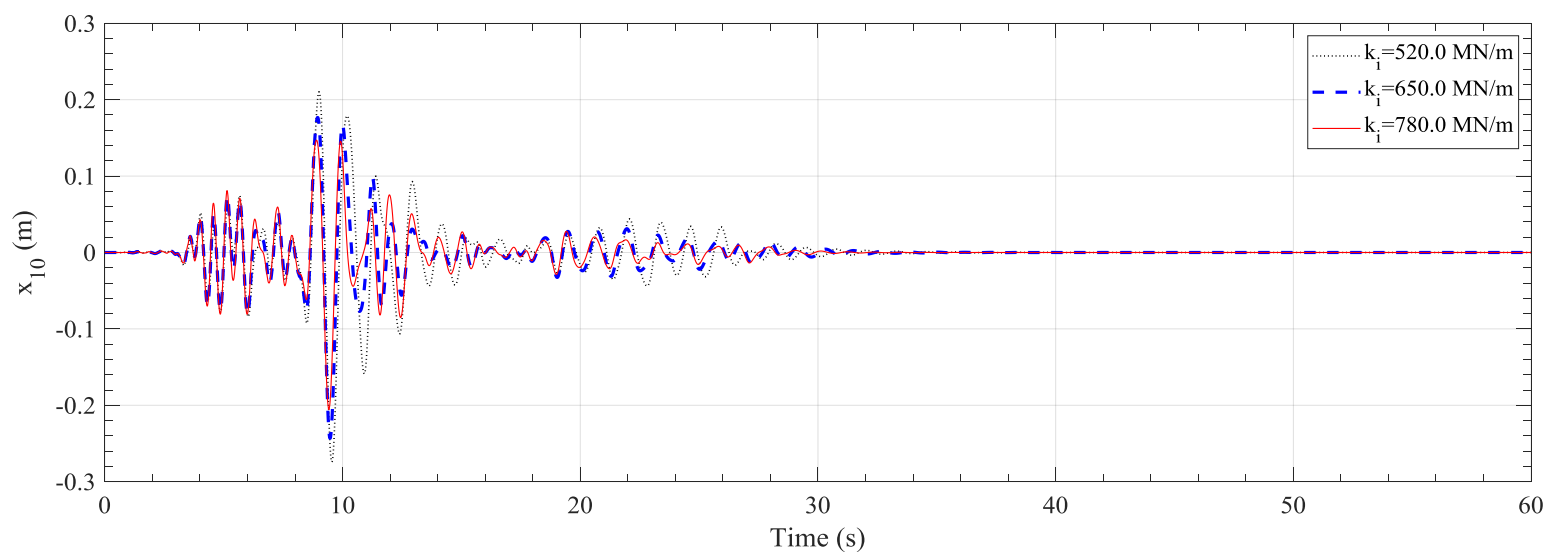

Fig. 1: Time history plots of top story displacements under NORTHR/MUL279 record.

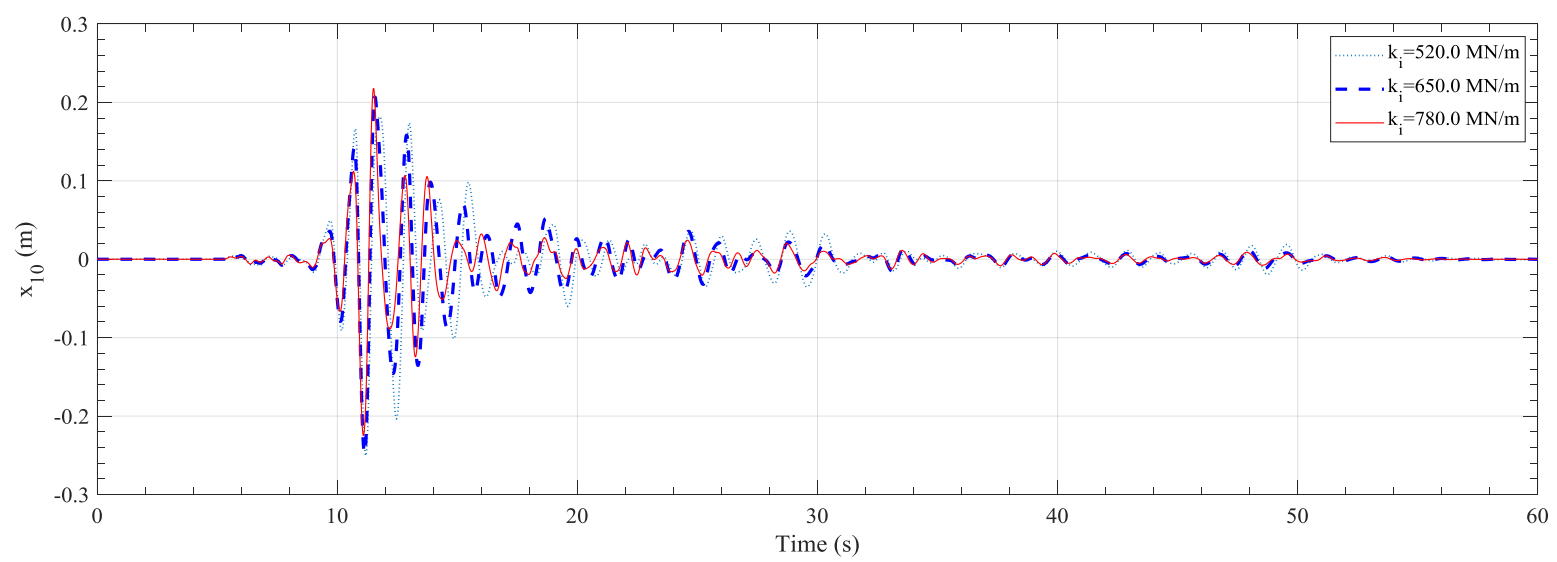

Fig. 2: Time history plots of top story displacements under DUZCE/BOL090 record.

\section{Conclusion}

Uncertainties in stiffness can be caused by many reasons such as design assumptions, differences in the behavior of the material (especially using nonhomogeneous materials such as concrete) or manufacturing errors. Depending on the quality of the control process during the construction of the structure, these uncertainties can be minimized, but it is not possible to completely eliminate.

For that reason, in this study, the performance, efficiency and robustness of the ATMD design, of which parameters are obtained under ideal conditions, in case of such uncertainties in the structural system are examined. Therefore 11 case analyzes are performed in which the story stiffness is changed between $-25 \%$ and $+25 \%$ with $\% 5$ increment. In the analyses, optimum ATMD parameters proposed by Kayabekir et al. [35] are considered and assumed to be constant in all cases.

The analysis results show that uncertainties in the structural stiffness can be an effect on ATMD performance. Since the design of ATMD is done based on structural stiffness, the effect of these uncertainties on structural behavior is an expected situation as can be also seen from Fig. 1 and 2. The critical earthquake may change due to variation of structural stiffness. Depending on changing critical earthquakes, the peak values of the structural responses and timing of the peak values can differ. These differences for the peak values of the story displacements are between $0.99 \%$ and $12.63 \%$. For the peak values of story accelerations, $8.47 \%$ $20.05 \%$ difference was observed.

In addition, the maximum displacements of the uncontrolled system are found $0.4101 \mathrm{~m}$ (DUZCE/ BOL090) and $0.4363 \mathrm{~m}$ (NORTHR/MUL279) for critical earthquake records. These displacements are reduced to 0.2469 (DUZCE/BOL090) and $0.2433 \mathrm{~m}$ (NORTHR/ MUL279) by the addition of ATMD to the structure. In this case, it can be said that the ATMD design is efficient and reliable even under stiffness uncertainties.

For future studies, these uncertainties are investigated on different models.

\section{References:}

[1] Ankireddi, S. and Y. Yang, H. T. (1996). Simple ATMD control methodology for tall buildings subject to wind loads, Journal of Structural Engineering, 122(1), 83-91. 
[2] Loh, C. H. and Chao, C. H. (1996). Effectiveness of active tuned mass damper and seismic isolation on vibration control of multistorey building, Journal of Sound and Vibration, 193(4), 773-792.

[3] Yan, N., Wang, C. M. and Balendra, T. (1999). Optimal damper characteristics of ATMD for buildings under wind loads, Journal of Structural Engineering, 125(12), 1376-1383.

[4] Aldawod, M., Samali, B., Naghdy, F. and Kwok, K. C. (2001). Active control of along wind response of tall building using a fuzzy controller, Engineering Structures, 23(11), 1512-1522.

[5] Samali, B., Al-Dawod, M., Kwok, K. C. and Naghdy, F. (2004) Active control of cross wind response of 76-story tall building using a fuzzy controller, Journal of engineering mechanics, 130(4), 492-498.

[6] Li, C., \& Liu, Y. (2002). Active multiple tuned mass dampers for structures under the ground acceleration, Earthquake engineering \& structural dynamics, 31(5), 1041-1052.

[7] Li, C., Liu, Y. and Wang, Z. (2003). Active multiple tuned mass dampers: A new control strategy, Journal of Structural Engineering, 129(7), 972-977.

[8] Han, B., and Li, C. (2006). Seismic response of controlled structures with active multiple tuned mass dampers, Earthquake Engineering and Engineering Vibration, 5(2), 205-213.

[9] Li, C. and Han, B. (2007). Control strategy of the lever-type active multiple tuned mass dampers for structures, Wind and Structures, 10(4), 301-314.

[10] Li, C. and Xiong, X. (2008). Estimation of active multiple tuned mass dampers for asymmetric structures, Structural Engineering and Mechanics, 29(5), 505-530.

[11] Pourzeynali, S., Lavasani, H. H. and Modarayi, A. H. (2007). Active control of high rise building structures using fuzzy logic and genetic algorithms. Engineering Structures, 29(3), 346-357.

[12] Guclu, R., and Yazici, H., 2008, Vibration control of a structure with ATMD against earthquake using fuzzy logic controllers, Journal of Sound and Vibration, 318(1-2), 3649.

[13] Guclu, R., and Yazici, H., 2009a, Seismicvibration mitigation of a nonlinear structural system with an ATMD through a fuzzy PID controller, Nonlinear Dynamics, 58(3), 553.

[14] Guclu, R., and Yazici, H., 2009b, Self-tuning fuzzy logic control of a non-linear structural system with ATMD against earthquake, Nonlinear Dynamics, 56(3), 199.

[15] Li, C., Li, J. and Qu, Y., 2010a, An optimum design methodology of active tuned mass damper for asymmetric structures, Mechanical Systems and Signal Processing, 24(3), 746-765.

[16] Li, C., 2012, Effectiveness of active multipletuned mass dampers for asymmetric structures considering soil-structure interaction effects, The Structural Design of Tall and Special Buildings, 21(8), 543-565.

[17] Venanzi, I. and Materazzi, A. L., 2012, Seismic Retrofitting of Irregular RC Buildings Using Active Tuned Mass Dampers, EACS2012, 5th Europ. Conf. on Structural Control,18-20 June 2012,Genoa, Italy.

[18] Venanzi, I., Ubertini, F. and Materazzi, A. L., 2013, Optimal design of an array of active tuned mass dampers for wind- exposed high- rise buildings, Structural Control and Health Monitoring, 20(6), 903-917.

[19] Sugumar, R., Kumar, C. and Datta, T. K., 2012b, Application of stochastic control system in structural control, Procedia engineering, 38, 2356-2363.

[20] Amini, F., Hazaveh, N. K. and Rad, A. A., 2013, Wavelet PSO-based LQR algorithm for optimal structural control using active tuned mass dampers, Computer-Aided Civil and Infrastructure Engineering, 28(7), 542-557.

[21] Fitzgerald, B., Basu, B., and Nielsen, S. R., 2013, Active tuned mass dampers for control of in-plane vibrations of wind turbine blades, Structural Control and Health Monitoring, 20(12), 1377-1396.

[22] Lu, X., Li, P., Guo, X., Shi, W. and Liu, J., 2014, Vibration control using ATMD and site measurements on the Shanghai World Financial Center Tower, The Structural Design of Tall and Special Buildings, 23(2), 105-123.

[23] Shariatmadar, H. and Meshkat Razavi, H., 2014, Seismic control response of structures using an ATMD with fuzzy logic controller and PSO method, Structural Engineering and Mechanics, 51.

[24] Soleymani, M. and Khodadadi, M., 2014, Adaptive fuzzy controller for active tuned mass damper of a benchmark tall building subjected to seismic and wind loads, The Structural Design of Tall and Special Buildings, 23(10), 781-800.

[25] Zabihi Samani, M., \& Amini, F. (2015). A cuckoo search controller for seismic control of a benchmark tall building. Journal of Vibroengineering, 17(3), 1382-1400. 
[26] Etedali, S., \& Tavakoli, S. (2017). PD/PID controller design for seismic control of highrise buildings using multi-objective optimization: a comparative study with LQR controller. Journal of Earthquake and Tsunami, 11(03), 1750009.

[27] Heidari, A. H., Etedali, S., and Javaheri-Tafti, M. R., 2018, A hybrid LQR-PID control design for seismic control of buildings equipped with ATMD, Frontiers of Structural and Civil Engineering, 12(1), 44-57.

[28] Park, K. S., \& Ok, S. Y. (2019). Coupling ATMD system for seismic response control of two adjacent buildings. Shock and Vibration, 2019.

[29] Li, C., \& Cao, L. (2019). High performance active tuned mass damper inerter for structures under the ground acceleration. Earthquakes and Structures, 16(2), 149-163.

[30] Khatibinia, M., Mahmoudi, M., \& Eliasi, H. (2020). Optimal sliding mode control for seismic control of buildings equipped with ATMD. Iran University of Science \& Technology, 10(1), 1-15.

[31] Kayabekir, A. E., Nigdeli, S. M., \& Bekdaş, G. (2021). A hybrid metaheuristic method for optimization of active tuned mass dampers. Computer- Aided Civil and Infrastructure Engineering.

[32] Kayabekir, A. E., Bekdaş, G., Nigdeli, S. M., \& Geem, Z. W. (2020a). Optimum Design of PID Controlled Active Tuned Mass Damper via Modified Harmony Search. Applied Sciences, 10(8), 2976.

[33] Kayabekir, A. E., Nigdeli, S. M., \& Bekdaş, G. (2020b). Robustness of Structures with Active Tuned Mass Dampers Optimized via Modified Harmony Search for Time Delay. In International Conference on Harmony Search Algorithm (pp. 53-60). Springer, Singapore.

[34] Aylin Ece Kayabekir, Sinan Melih Nigdeli, Gebrail Bekdaş, "Active Tuned Mass Dampers for Control of Seismic Structures," WSEAS Transactions on Computers, vol. 19, pp. 122128, 2020

[35] Kayabekir, A. E. (2021). Metasezgisel Algoritmalar ile Optimize Aktif Ayarlı Kütle Sönümleyicileri ile Yapilarin Kontrolü, $\mathrm{PhD}$ Thesis, Istanbul University - Cerrahpaşa, Istanbul, Turkey.

[36] T. Sudha, D. Subbulekshmi, "Flower Pollination Optimization Based PID Controller Tuning Scheme With Robust Stabilization of Gain Scheduled CSTR," WSEAS Transactions on Heat and Mass Transfer, vol. 15, pp. 1-10, 2020

[37] Osama El-baksawi, "Whale Optimization Algorithm for Maximum Power Point Tracker for Controlling Induction Motor Driven by Photovoltaic System," WSEAS Transactions on Power Systems, vol. 14, pp. 70-78, 2019

[38] M. Mohamed Iqbal, R. Joseph Xavier, J. Kanakaraj, "Optimization of droop setting using Genetic Algorithm for Speedtronic Governor controlled Heavy Duty Gas Turbine Power Plants," WSEAS Transactions on Power Systems, vol. 11, pp. 117-124, 2016

[39] Anwar Haider, Ali Al-Mawsawi, Ahmed AlQallaf, "Evolutionary Optimization Algorithms in Designing a UPFC Based POD Controller," WSEAS Transactions on Power Systems, vol. 11, pp. 100-110, 2016

[40] Maad Shatnawi, Ehab Bayoumi, "Simulated Annealing Optimization of PMBLDC Motor Speed and Current Controllers," WSEAS Transactions on Power Systems, vol. 15, pp. 191-205, 2020

[41] FEMA (2009), P-695: Quantification of Building Seismic Performance Factors. Washington, USA.

[42] The Math Works, Inc., MATLAB, version 2018a, Natick, MA.

\section{Contribution of Individual Authors to the Creation of a Scientific Article (Ghostwriting Policy)}

Aylin Ece Kayabekir, Gebrail Bekdaş and Sinan Melih Nigdeli generated the analysis code.

Aylin Ece Kayabekir done the analysis and drew the figures.

The text of the paper was composed by Aylin Ece Kayabekir, Gebrail Bekdaş and Sinan Melih Nigdeli.

Creative Commons Attribution License 4.0 (Attribution 4.0 International, CC BY 4.0)

This article is published under the terms of the Creative Commons Attribution License 4.0 https://creativecommons.org/licenses/by/4.0/deed.en _US 